\title{
Simulation of the Impacts of Urbanization on Winter Meteorological Fields over the Pearl River Delta Region
}

\author{
Naixing Luo, ${ }^{1,2}$ Liping Zeng, ${ }^{3}$ Wenshi Lin, ${ }^{1,4}$ Fangzhou Li, ${ }^{1}$ Baolin Jiang, ${ }^{1}$ and Jiangnan Li ${ }^{1}$ \\ ${ }^{1}$ School of Atmospheric Sciences, Sun Yat-sen University, Guangzhou 510275, China \\ ${ }^{2}$ Guiyang Bureau of Meteorology, Guiyang 550001, China \\ ${ }^{3}$ Guizhou Meteorological Bureau, Guiyang 550002, China \\ ${ }^{4}$ Guangdong Province Key Laboratory for Climate Change and Natural Disaster Studies, Sun Yat-sen University, \\ Guangzhou 510275, China
}

Correspondence should be addressed to Wenshi Lin; linwenshi@mail.sysu.edu.cn and Jiangnan Li; essljn@mail.sysu.edu.cn

Received 29 May 2017; Revised 29 September 2017; Accepted 9 October 2017; Published 15 November 2017

Academic Editor: Anthony R. Lupo

Copyright (C) 2017 Naixing Luo et al. This is an open access article distributed under the Creative Commons Attribution License, which permits unrestricted use, distribution, and reproduction in any medium, provided the original work is properly cited.

The influences of urbanization on weather in Guangdong Province, China, were studied using the Weather Research and Forecasting model from 31 December 2009 through 3 January 2010. Model outputs were compared with extensive monitoring of meteorological data to examine the simulation ability. Model results between tests (with and without land-use change) show that the urbanization had major effects on meteorological fields across nearly the entire Pearl River Delta region and particularly in urban areas. Studied fields (wind speed, temperature, precipitation, and sensible and latent heat fluxes) were affected by the urbanization of the PRD region. The major influences occurred in urban areas, where wind speeds decreased greatly, while the daytime surface upward sensible heat flux clearly increased. Unlike the sensible heat flux, the latent heat flux had a nonmonotonic increase or decrease. As a consequence of the two heat fluxes, 2-m temperature varied with location and time. Change of precipitation was complex. The main rain band became more concentrated, while precipitation decreased upwind of the urban area and increased downwind.

\section{Introduction}

During the past 20 years, the Pearl River Delta (PRD) region has experienced rapid economic development. Simultaneously, there has been tremendous urban sprawl, and this trend is expected to continue in the future. This has brought about a series of changes, such as dramatic change of land use and increased emissions of anthropogenic pollution. Urban expansion has influenced the atmosphere of cities by releasing more pollutants, altering surface energy balances, and forming urban heat islands (UHIs), thereby affecting the thermal stratification of the urban boundary layer and localscale circulation patterns [1]. The expansion of urban land use is one of the key issues in the region, because it could greatly alter the dynamic and thermodynamic character of the underlying surface.

A series of observations and model simulations have shown that, in urban extensions, urban land use can produce unique dynamic and thermodynamic characteristics.
Recent research using the Weather Research and Forecasting (WRF) model has shown that, with increasing urban surface roughness, wind speed over the city area is weaker than its surrounding countryside; at $10 \mathrm{~m}$ height, there is a $20 \%$ reduction. This may even impact the pollution cycle [2]. Some researchers have shown that land use plays a key role in the local sea-land breeze circulation [3]. The authors of [4] found that the UHI can strengthen the daytime sea breeze and weaken the nighttime land breeze. These characteristics can lead to an urban canopy layer, greatly affecting the meteorology in an urban area and its surroundings [5].

Observations have shown that, under clear skies and light wind, cities are warmer than surrounding rural environments by as much as $4^{\circ} \mathrm{C}$, generating the UHI from urban-rural differences [6-8]. A recent study using the MM5 (short for Fifth-Generation Penn State/NCAR Mesoscale Model) atmospheric model has shown that such differences in the PRD can substantially raise the monthly average temperature by $0.6^{\circ} \mathrm{C}$ [9]. Furthermore, there is strong evidence 
that urban areas can alter precipitation patterns. Through analyzing and fitting probability distributions to the data of Beijing automatic weather stations across both urban and suburban areas, the authors of [10] stated that the effect of urbanization on short-duration precipitation is mainly to increase precipitation downwind of the urban area. The result of [11] shows that total accumulated precipitation in the entire simulated domain decreased, especially in the urbanized area, because of the increased surface roughness. These urban-rural differences profoundly modify surface energy budgets, which can change the mixed-layer depth and thermal structures in the boundary layer $[12,13]$.

In contrast with other periods, there is a lack of research into the above impacts in winter. Our overall objective in this study was to investigate the impact of urbanization on meteorology during the winter rainfall period. In order to investigate the comprehensive impact of urbanization, a mesoscale atmospheric model (the WRF model) was used to simulate the precipitation event of 31 December 2009 through 3 January 2010. The remainder of the paper is organized as follows. In Section 2, we describe the numerical modeling setup used. A brief discussion of numerical experiments is also provided. Section 3 addresses results of the simulation and impacts of urbanization on meteorological conditions (including wind, precipitation, and temperature). Summary and concluding remarks are presented in Section 4.

\section{Description of Model and Numerical Experiments}

The Weather Research and Forecasting (WRF) model coupled with a single-layer urban canopy model (UCM) [14] was used to simulate winter rainfall in the PRD. We incorporated the Advanced Research WRF (WRF-ARW) dynamical core described by [15] for the three two-way interactive nested domains shown in Figure 1(a). The grid spacings of these computational domains were $36 \mathrm{~km}(106 \times 121), 12 \mathrm{~km}(100 \times$ $100)$, and $4 \mathrm{~km}(124 \times 124)$ and were called D01, D02, and D03, respectively. The coarse outer domain, D01, comprises a large portion of China and extends well south into the South China Sea, and the second domain, D02, covers all of Guangdong Province. To better capture urbanization influences on the $\mathrm{PRD}$, a $4 \mathrm{~km}$ grid in conjunction with high-resolution landuse maps was used for the inner domain D03. There is a gentle increase in terrain height $(\sim 400 \mathrm{~m})$ from cities to surrounding rural areas in the PRD. Pressure at the model top, where a radiative boundary condition is used, was $50 \mathrm{hPa}$. The vertical grid contained 31 sigma levels. The lowest halfsigma level was $\sim 40 \mathrm{~m}$ above the ground. The lowest nine levels were below $1 \mathrm{~km}$ because the major target of the study was within the boundary layer.

The Bougeault and Lacarrere (BEP) planetary boundary layer (PBL) scheme and its urban canopy model [14] were used in all domains. The new Grell cumulus parameterization scheme [16] was selected for all three domains. A highresolution cloud microphysical scheme that considers rain, snow, cloud water, and cloud ice was also used in all domains [17]. The Noah land surface model (LSM) based on the Oregon State University version was used [18]. The LSM predicts volumetric soil moisture and temperature in four soil layers. Depths of those layers from top to bottom are 0.1, 0.3, 0.6 , and $1.0 \mathrm{~m}$. This could depict heat and dynamic features of the urban surface. We also used the Rapid Radiative Transfer Model scheme for longwave radiation [19] and the Goddard shortwave scheme for shortwave radiation [20].

Initial and boundary conditions were interpolated from the National Centers for Environmental Prediction (NCEP) final reanalysis (FNL) data (https://rda.ucar.edu/datasets/ ds083.2/) to the WRF coarse domain (D01) with horizontal grid spacing of $36 \mathrm{~km}$ and 31 sigma levels in the vertical. Conventional surface and upper-air observation data were incorporated into the analysis using a Cressman-type analysis scheme. Initial conditions for the two inner domains were obtained by interpolating from the outer domain. The simulation started at 0000 UTC 31 December 2009 and ended at 0000 UTC 3 January 2010. The first 12-h simulation was used for spin-up.

Two land-use scenarios were used in the case study of the PRD region within simulation domain D03 to explore the effect of urban expansion. The United States Geological Survey (USGS) global land-use map in WRF is based on 1992-1993, 1-km Advanced Very High-Resolution Radiometer (ADVHRR) data (Figure 1(b)), which to a substantial degree reflects the distribution of cities (mainly Guangzhou and Hong Kong) in the PRD region during the late 1980s. However, updated land use based on 2004 Moderate Resolution Imaging Spectroradiometer land-use and land-cover data (MODIS LULC) data was used to characterize the distributions of cities in the PRD (Figure 1(c)), with rapidly urbanizing areas centered on Guangzhou, Foshan, Dongguan, and Shenzhen. The land-use distribution of MODIS LULC data is different from that of USGS data.

With the urban canopy model coupled to WRF, two simulations were conducted using the same initial and lateral boundary conditions, physics packages, and configurations. The only difference between the two simulations was the land-use cover. That is, the control simulation (PRE-URBAN) used the USGS AVHRR land-use cover mimicking the PRD land-use distribution prior to rapid urbanization and industrial development over the last two decades, whereas the sensitivity simulation (URBAN) used the MODIS LULC data with updated urban distribution more representative of the present.

\section{Simulation Results}

In this section, the results at $36-\mathrm{km}$ grid spacing are presented at three times to examine the capability of the PRE-URBAN simulation. In separate subsections, the results of two simulations at $4 \mathrm{~km}$ grid spacing are used to address the impacts of urbanization on wind, precipitation, and temperature.

3.1. Large-Scale Fields of PRE-URBAN Simulation. Among meteorological factors, large-scale surface wind and pressure fields as major synoptic conditions can effectively portray the large-scale meteorological situation and alter the local meteorological state. In this section, we use pressure fields 


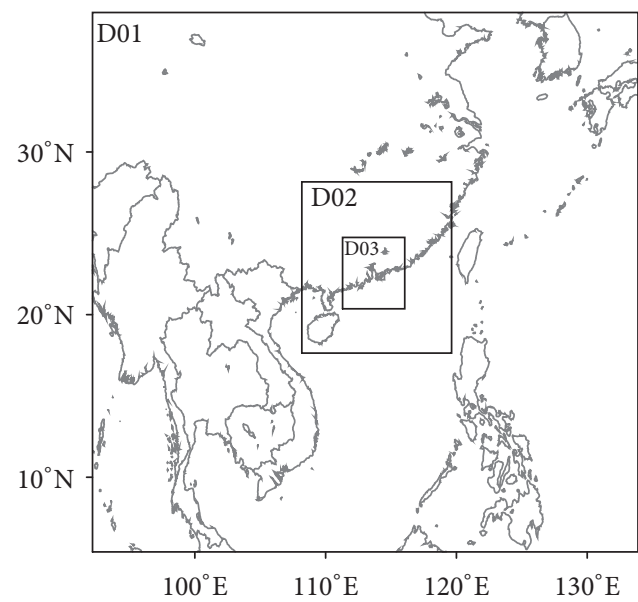

(a)

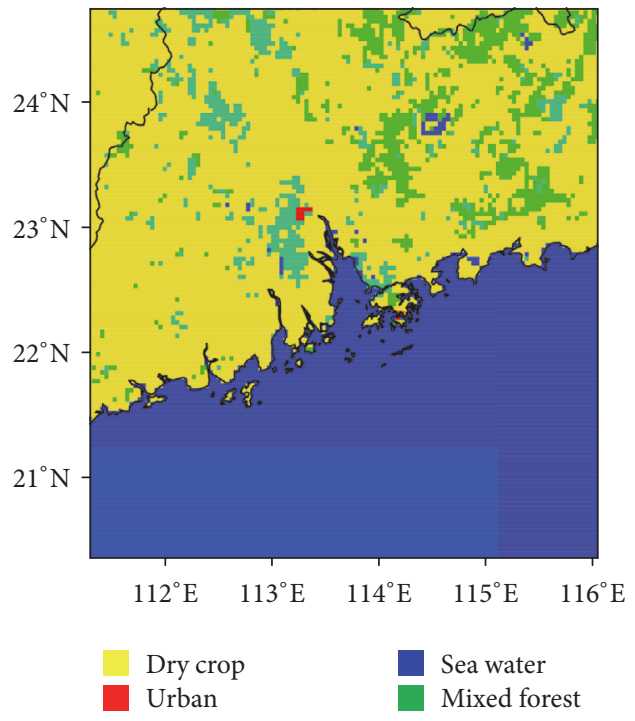

(b)

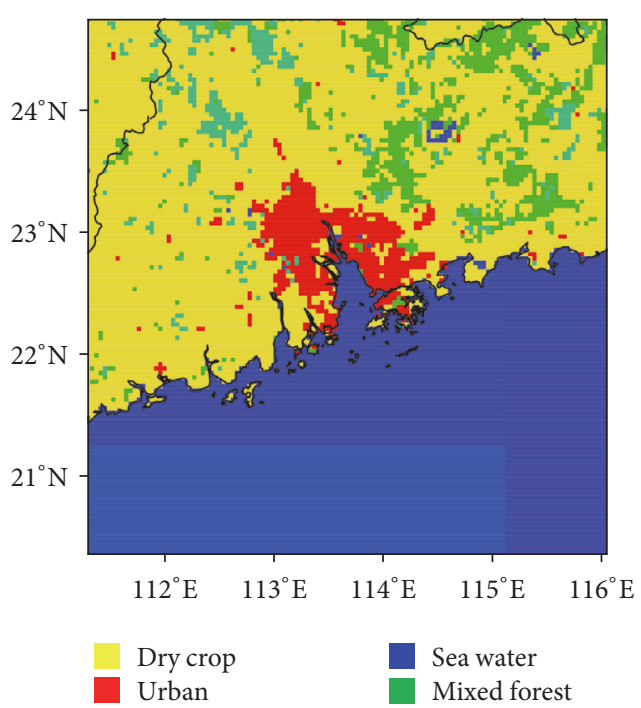

(c)

FIGURE 1: WRF model nested domains and land use for simulations. (a) WRF nested domains. Domain 1 (D01): 36-km grid spacing; Domain 2 (D02): $12 \mathrm{~km}$ spacing; Domain 3 (D03): $4 \mathrm{~km}$ spacing. (b) USGS 1992-1993 data used in PRE-URBAN test D03. (c) MODIS 2001 data in URBAN test D03.

in domain D01 to verify the ability of the PRE-URBAN simulation.

In the period of 31 December 2009 to 3 January 2010, the PRD region was controlled by two major high-pressure systems successively (the eastward-moving Changjiang-Huaihe River High and the southward-moving North China High, as in Figure 2). At 12:00 UTC 31 December 2009, the PRD region was located at the bottom of the Changjiang-Huaihe River High which moved eastward to the East China Sea (Figure 2(a)). On the last day (2 January), the Yangtze River Delta and South China were occupied by the southwardmoving North China High (Figure 2(e)). Under the effect of the southeastward-moving North China High, the pressure in the PRD region was between the 1015 and $1020 \mathrm{hPa}$ contours, but the $10 \mathrm{~m}$ wind in the region changed from east to northeast.
The PRE-URBAN simulation accurately captured the location and range of the two major high-pressure systems. Since the two major high-pressure areas were captured well, the simulated horizontal wind was reasonably consistent with the observations in both wind speed and wind direction (Figures 2(b), 2(d), and 2(f)).

3.2. Influences of Urban Expansion on Wind Fields. The prevailing wind direction changed from eastward (12:00 UTC on 31 December 2010) to southeastward (18:00 on 1 January UTC and 12:00 on 1 January UTC), finally becoming eastward at 18:00 on 2 January 2010. According to the results, the wind field had a strong relationship with surface roughness in low layers.

Figure 3 shows that wind speed decreased more than $3 \mathrm{~m} \mathrm{~s}^{-1}$ in the PRD regions. Though the wind speed weakened 


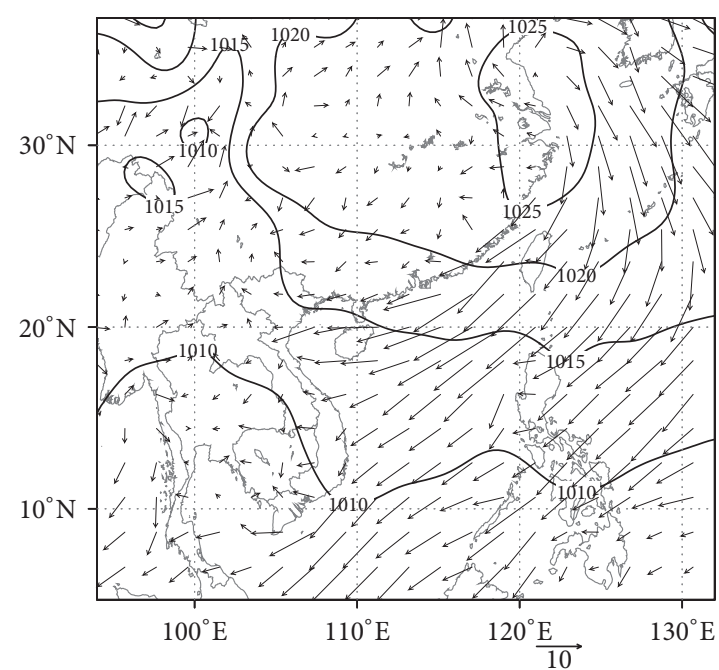

(a)

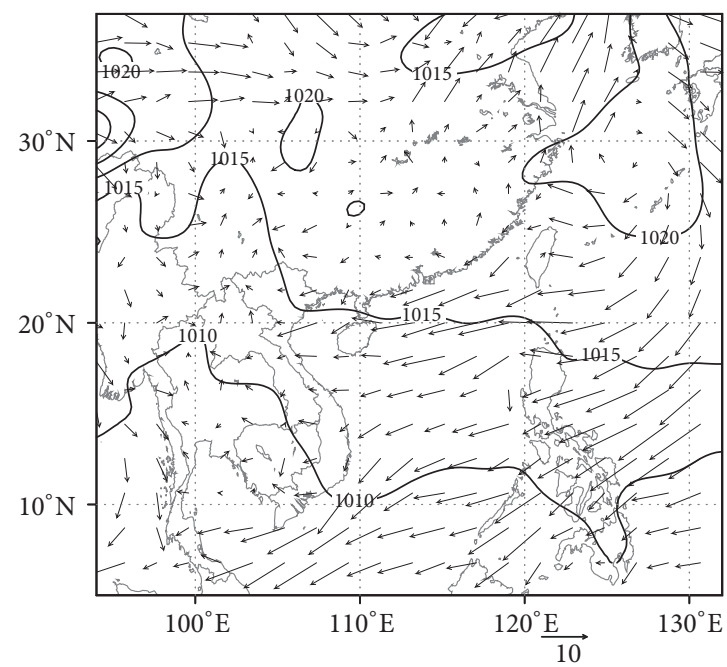

(c)

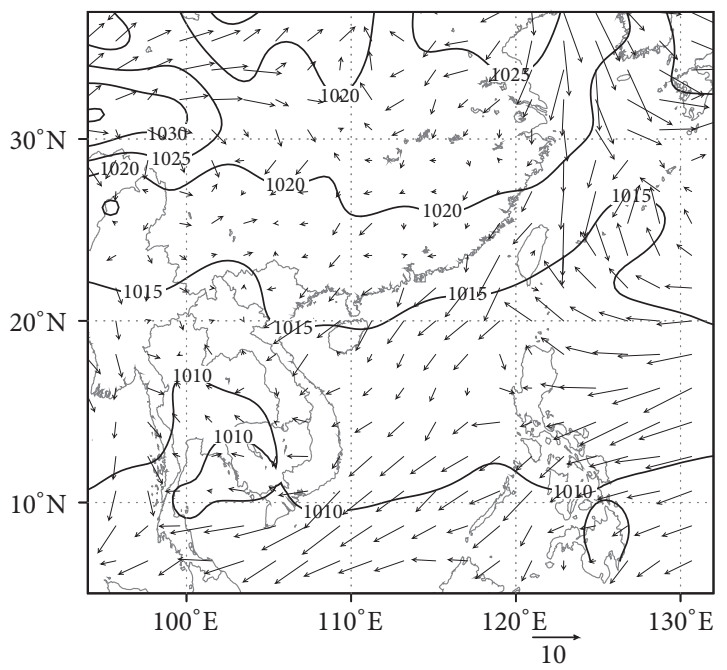

(e)

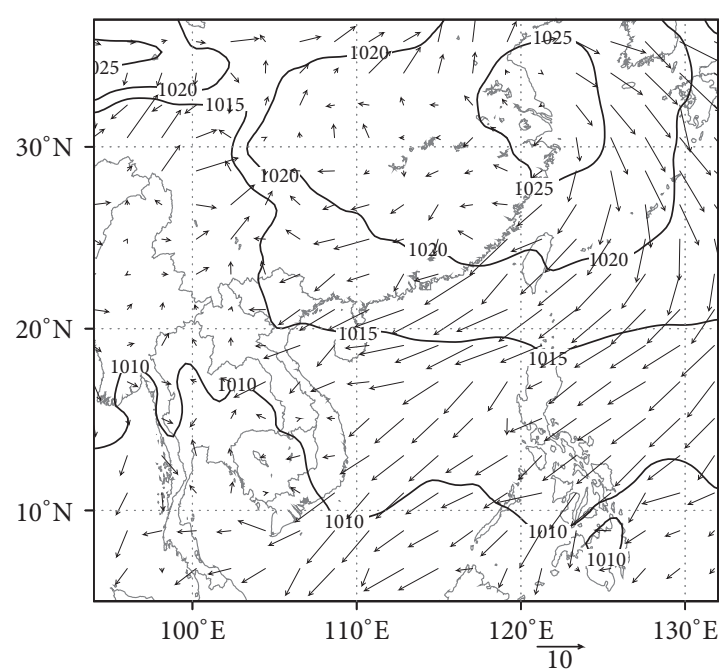

(b)

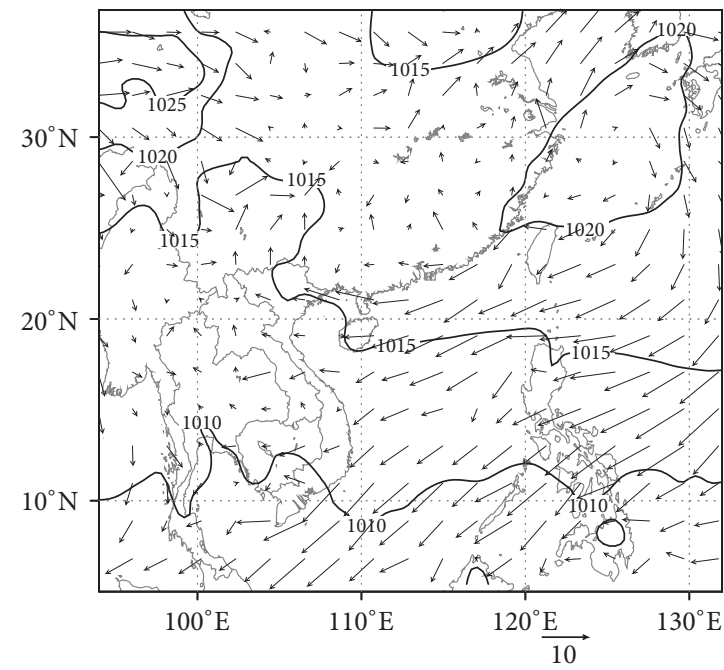

(d)

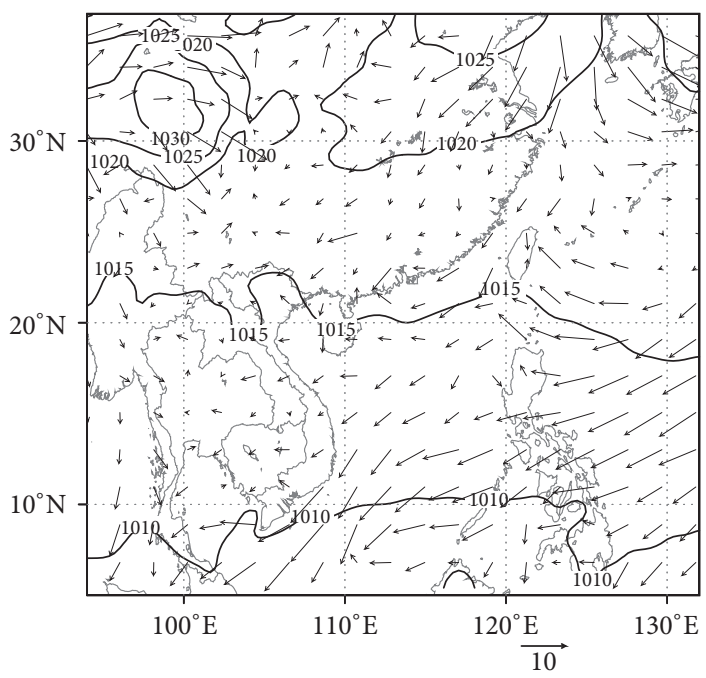

(f)

FIGURE 2: Sea level pressure (unit: hPa) and wind distribution (unit: $\mathrm{m} \mathrm{s}^{-1}$ ) at 12:00 on 31 December 2009 (UTC) for (a) NCEP data and (b) PRE-URBAN test, 12:00 on 1 January 2010 (UTC) for (c) NCEP data and (d) PRE-URBAN test, 12:00 on 2 January 2010 (UTC) for (e) NCEP data and (f) PRE-URBAN test. 


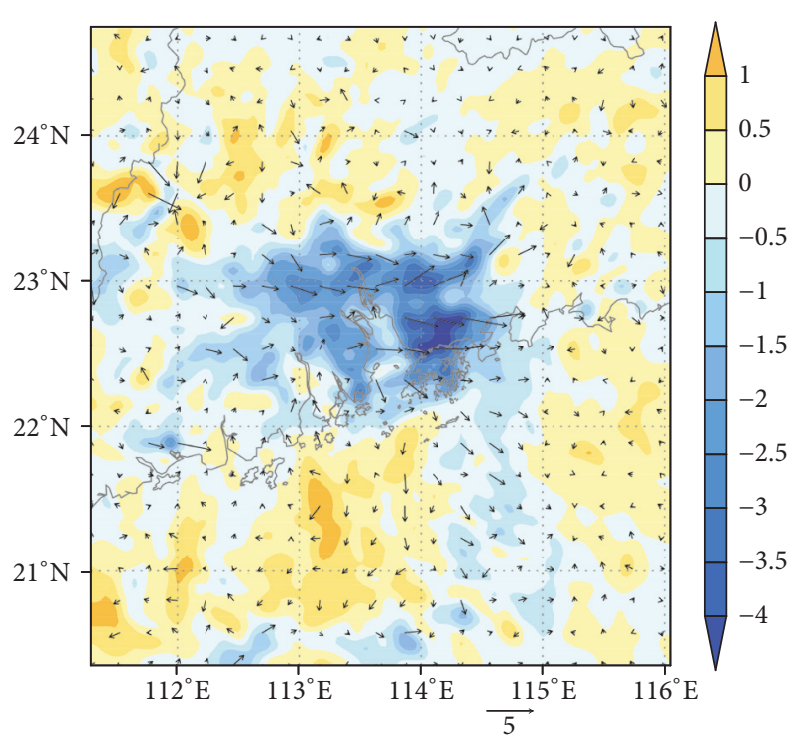

(a)

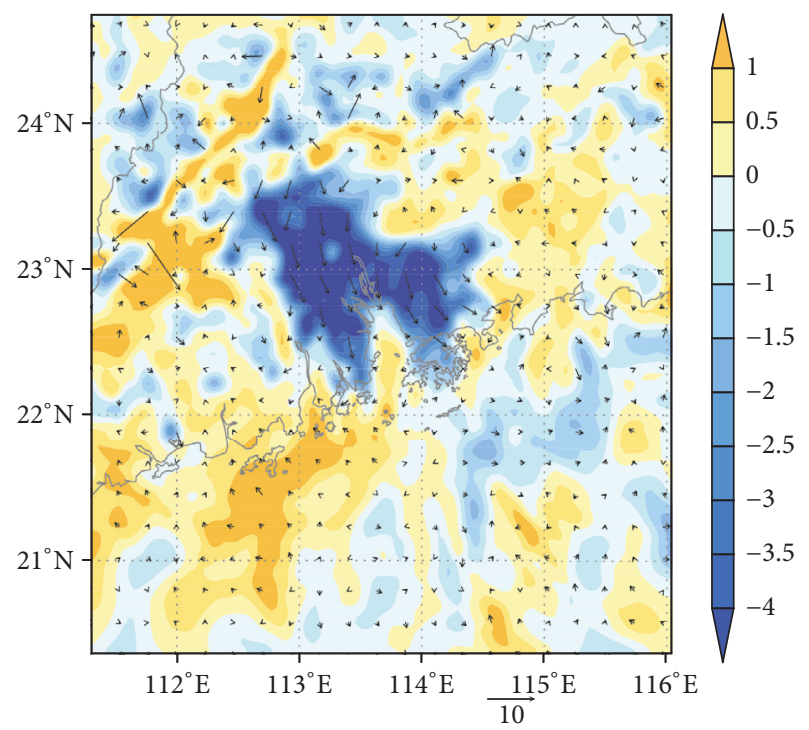

(c)

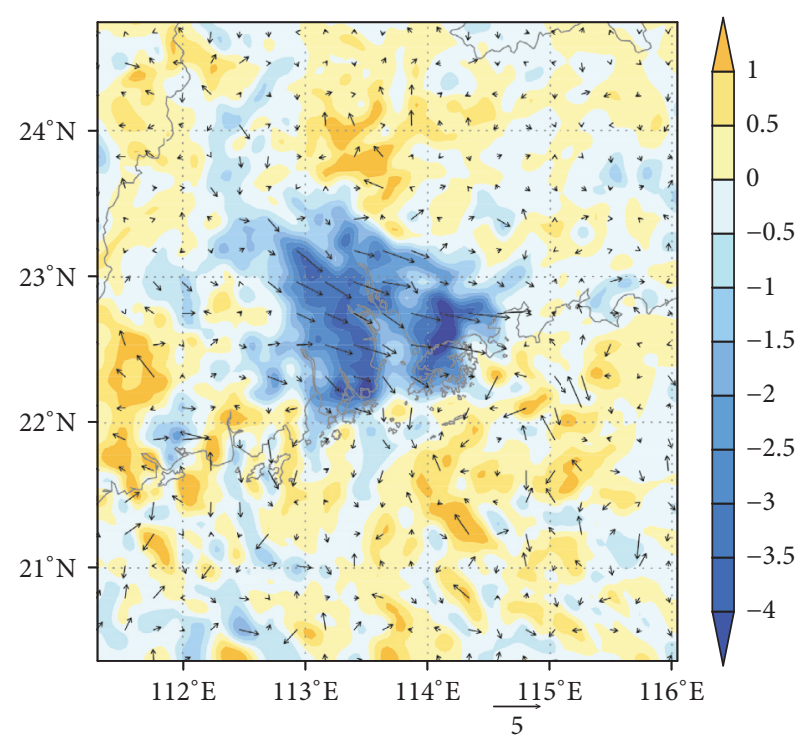

(b)

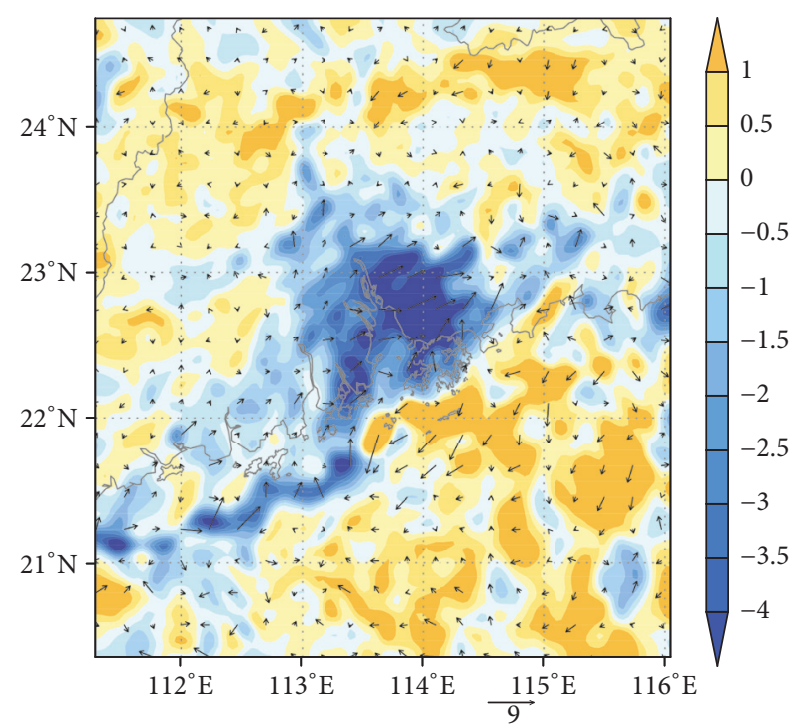

(d)

FIGURE 3: Differences of $10 \mathrm{~m}$ wind and wind speed (choropleth map, unit: $\mathrm{m} \mathrm{s}^{-1}$ ) between URBAN and PRE-URBAN test (URBAN minus PRE-URBAN) for daytime (06:00 UTC) and nighttime (18:00 UTC), during 1-2 January 2010. (a) 06:00 on 1 January, (b) 18:00 on 1 January, (c) 14:00 on January, and (d) 18:00 on 2 January.

drastically, it appeared that urbanization did not alter the wind direction (i.e., that direction remained the same as in the PRE-URBAN simulation).

3.3. Influences of Urban Expansion on Precipitation. Along with the southward-moving cold air, the main rain belt moved into the PRD region on 2 January. The belt was in a long and narrow area from $24^{\circ} \mathrm{N}, 116^{\circ} \mathrm{E}$ to $22.5^{\circ} \mathrm{N}, 111.5^{\circ} \mathrm{E}$ (Figures 4(a) and 4(b))

Urban impacts on the 24-h accumulated precipitation are shown in Figure 4(c). These impacts have two major features. As mentioned before, the prevailing wind on the last day was mainly northeasterly or easterly, so the region east of the PRD could be seen as an upwind area and the other side as a downwind area. The first feature concerns the major rain belt. Owing to urbanization, the upwind rain belt had a wider extent, and precipitation in its downwind part increased by nearly $8 \mathrm{~mm}$. The second feature is related to precipitation in the urban area. The obvious change was to precipitation intensity. Precipitation upwind of the urban area decreased but increased downwind.

3.4. Influences of Urban Expansion on Temperature. Figure 5 shows the influence of urbanization on surface temperature 


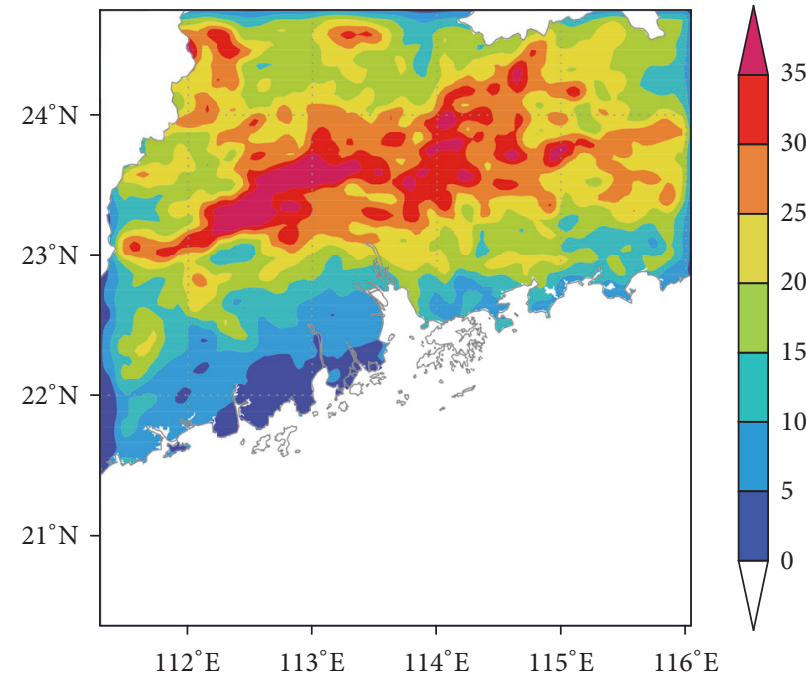

(a)

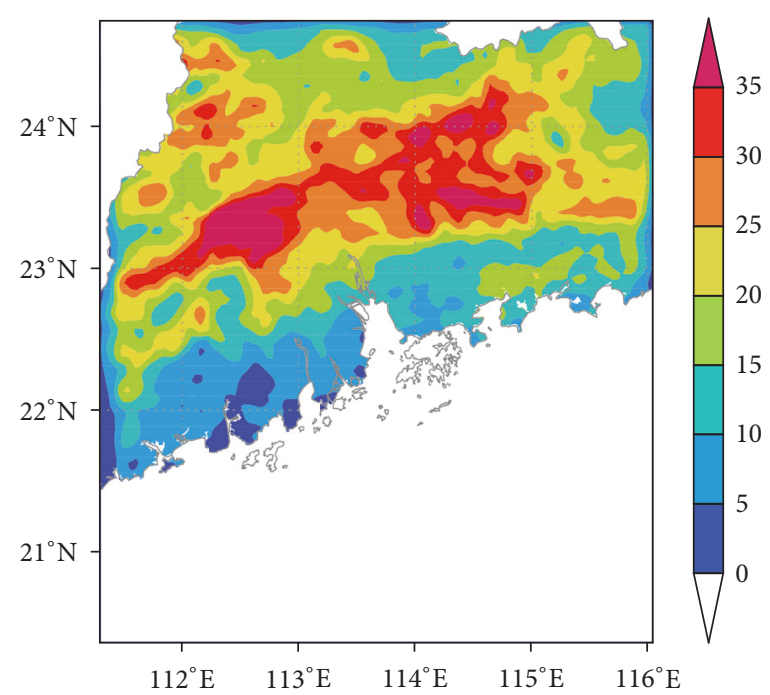

(b)

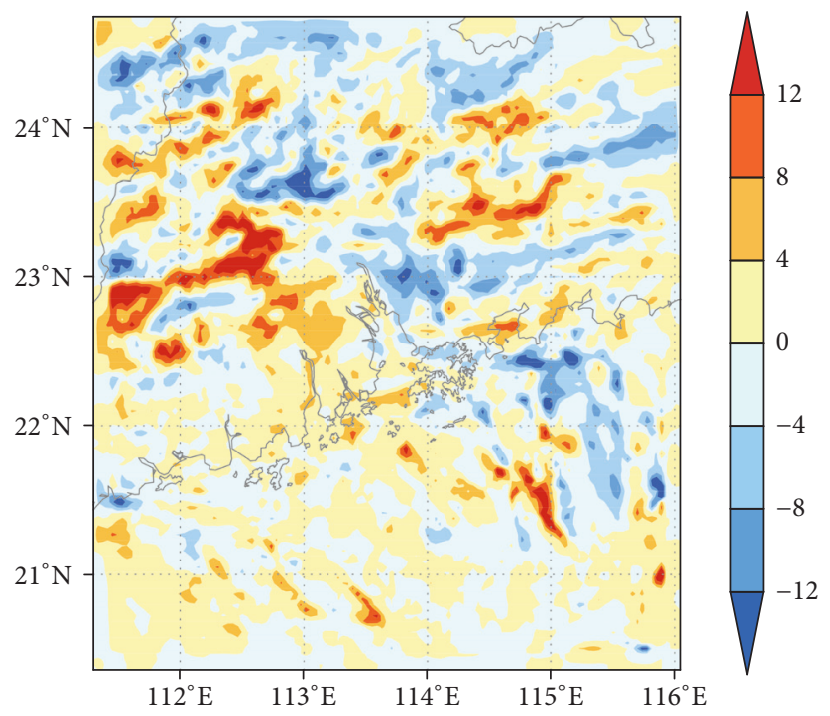

(c)

FIGURE 4: 24-h accumulated precipitation distribution (unit: $\mathrm{mm}$ ) in PRE-URBAN (a) and URBAN (b) simulations from 0000 (UTC) on 2 January to 0000 (UTC) on 3 January 2010. (c) Differences of 24-h accumulated precipitation (unit: mm) between URBAN and PRE-URBAN simulations (URBAN minus PRE-URBAN) from 0000 (UTC) on 2 January to 0000 (UTC) on 3 January 2010.

during daytime and nighttime. At 0600 UTC 1 January 2010, surface temperature in the PRD urban area from the URBAN simulation was clearly warmer than from the PREURBAN simulation. The BEP urban model used in this work allows the underlying urban surface to store heat in daytime and release it at night, which means that it facilitates the mechanism of the UHI. Thus, even with the UCM model facilitating the UHI, an urban cold island was simulated. This implies that this effect does not have the major role in producing the UHI.

As the major heat source of air at $2 \mathrm{~m}$, the upward heat flux was split into two components (ground upward sensible and latent heat fluxes) to treat direct and indirect heat fluxes separately. Figures 6 and 7 show changes of USHF (ground upward sensible heat flux) and ULHF (ground upward latent heat flux) caused by urbanization, respectively.

The USHF had a positive effect during daytime on the urban area and its downwind suburbs. As Figure 6 shows, the impact of urbanization was mainly limited to those regions, with a shape similar to that of the wind field. The intensity of 1-hour USHF in the urban area was $\sim 80 \mathrm{~W} \mathrm{~m}^{-2}$ in the daytime on 1 January and $20 \mathrm{~W} \mathrm{~m}^{-2}$ in daytime on 2 January, which is inversely proportional to precipitation. Besides the above areas, other land areas had largely negative values in daytime. At night, the impact was very weak, although the urban area had positive values. The ULHF shown in Figure 7 reveals a different sense. As shown in the figure, the impact of urbanization served as negative reinforcement 


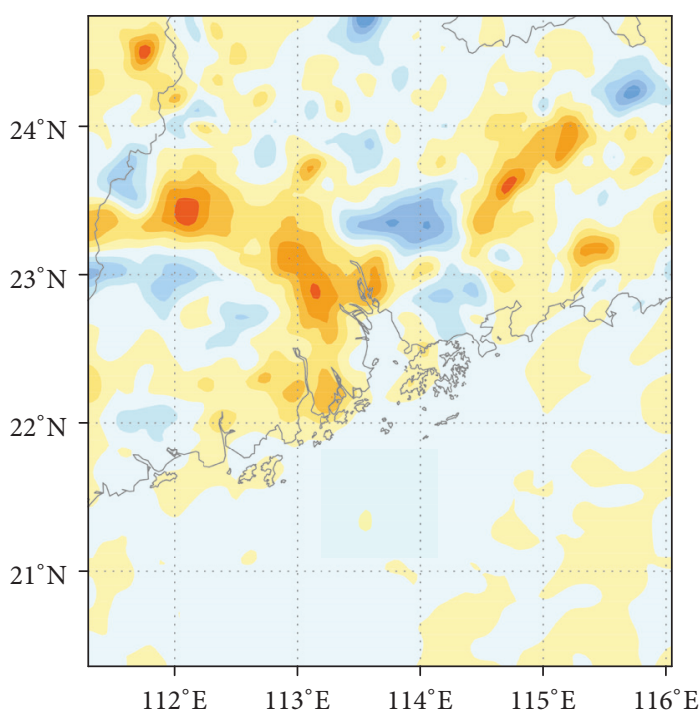

(a)

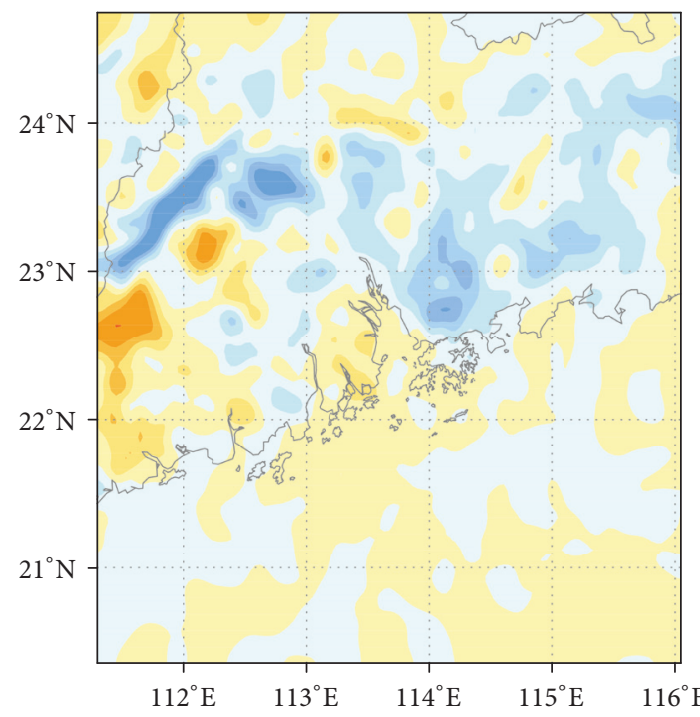

(c)

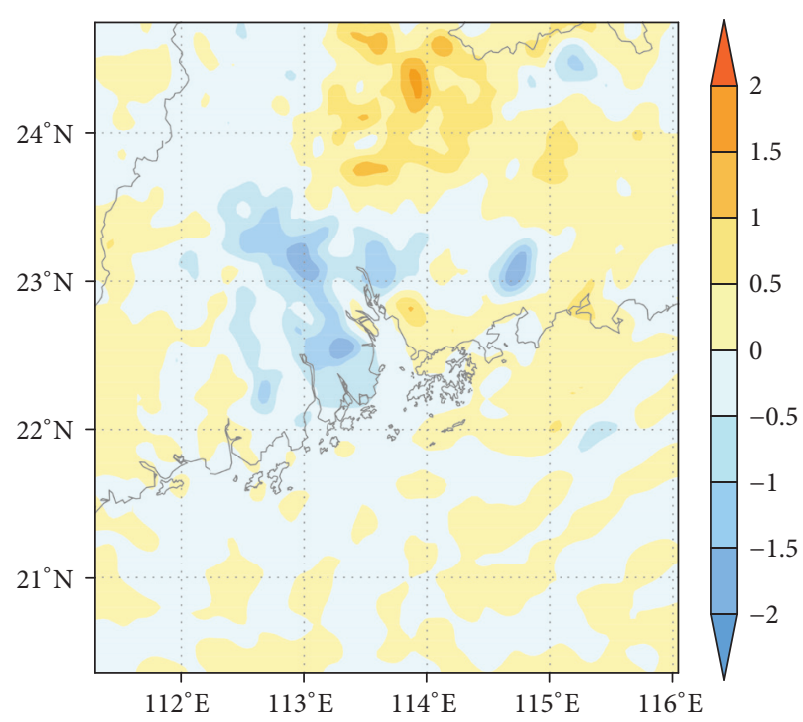

(b)

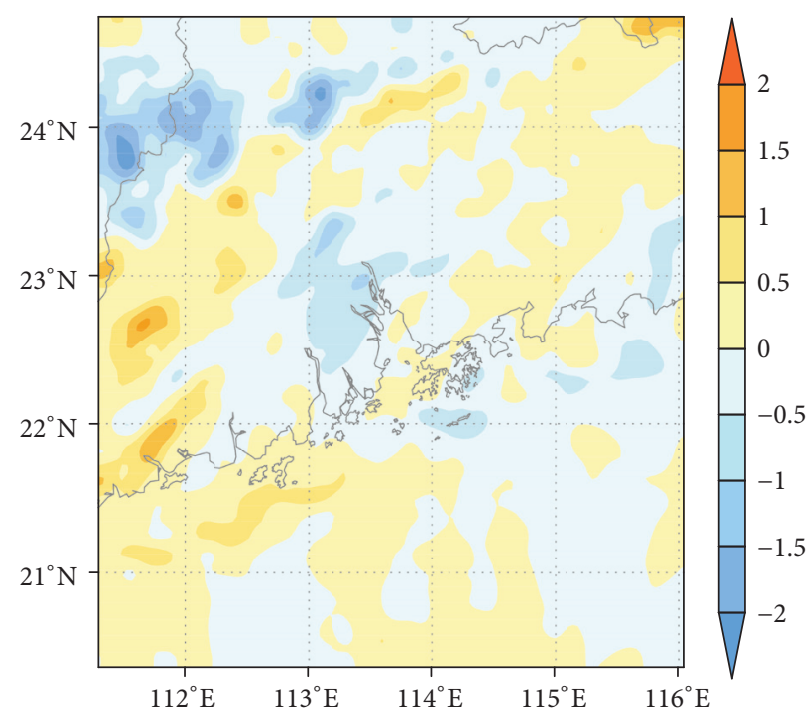

(d)

Figure 5: As in Figure 3, but for 2-m temperature. Unit is ${ }^{\circ} \mathrm{C}$.

during daytime in the urban area and its downwind suburbs. In contrast with the USHF, the average reduction was similar in the urban area on 1 and 2 January, which was around $-40 \mathrm{~W} \mathrm{~m}^{-2}$. At night, it is similar but even weaker (below $-20 \mathrm{~W} \mathrm{~m}^{-2}$ ).

The above analyses indicate that the impact of 2-m temperature was the result of the USHF and ULHF. Therefore, on 1 January, because the positive reinforcement of the USHF was strong, the overall impact was to increase the 2-m temperature in the urban area. Owing to the weak positive reinforcement of the USHF, the overall impact was negative on 2 January, when the major precipitation occurred. At night, with the negative reinforcement of the ULHF playing the major role, the urban area had a slight decrease of 2-m temperature.

\section{Summary and Conclusions}

The PRD region has experienced remarkably fast economic development and urban expansion in the past two decades, forming a virtual PRD city cluster with a substantial area of modified underlying surface and a population increase by millions. A series of model simulations searched the meteorological changes caused by the urban expansion in the time of warmth and no precipitation.

In this work, the meteorological changes are caused by urban expansion in a rainy winter case, by using the mesoscale atmospheric WRF-coupled BEP UCM models. In this case study (31 December 2009 through 3 January 2010), two types of urban land-use database (representing 1980s and 2004 urban land-use cover in the PRD) were used with 


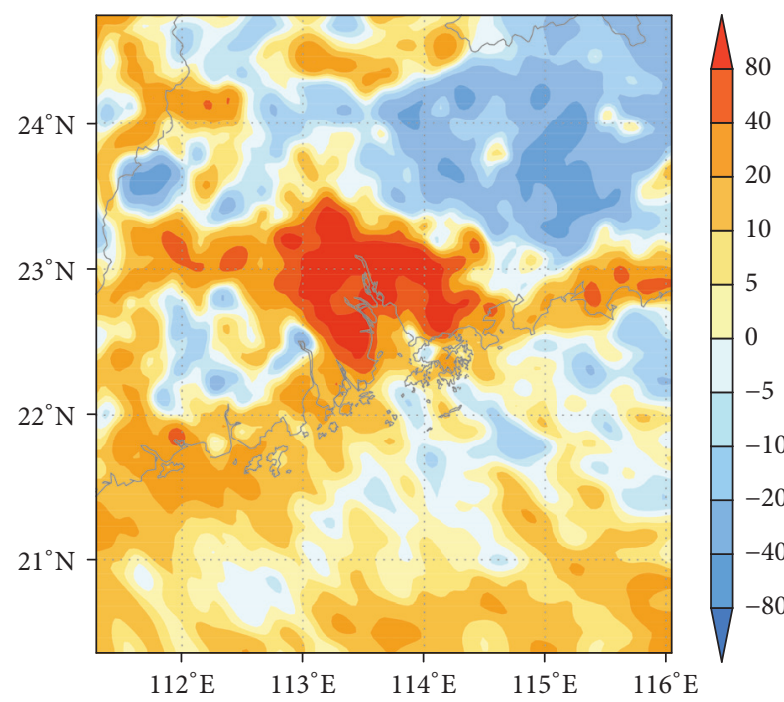

(a)

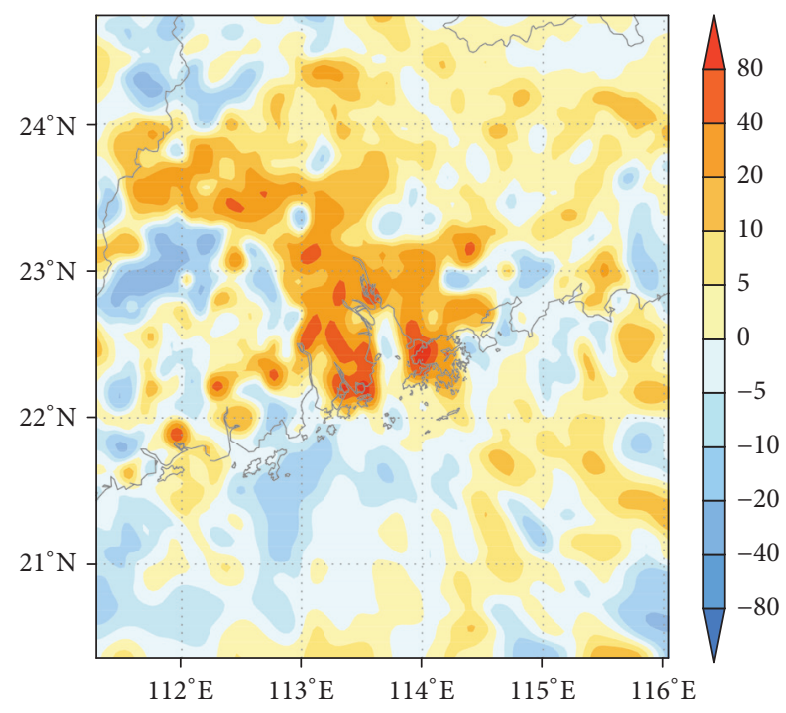

(c)

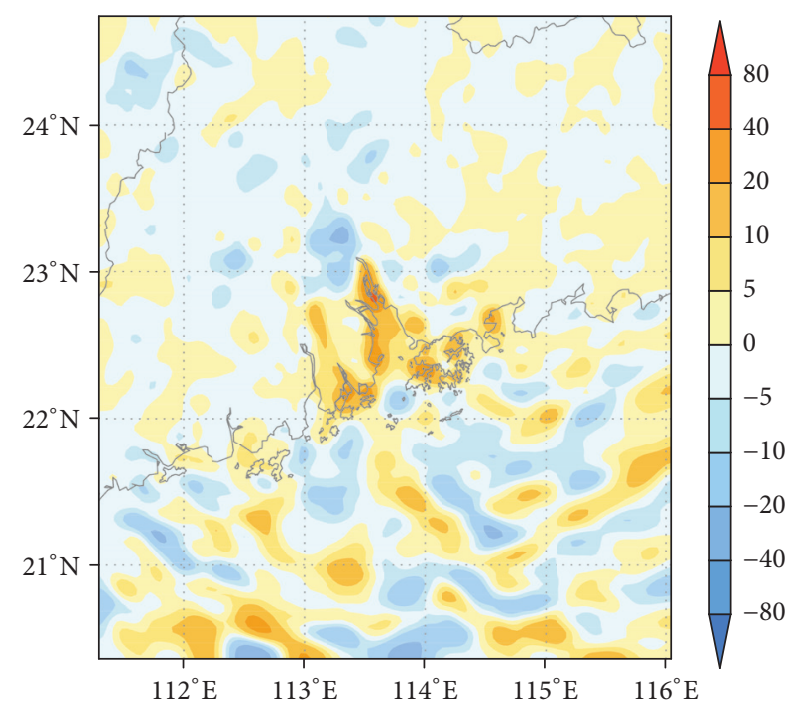

(b)

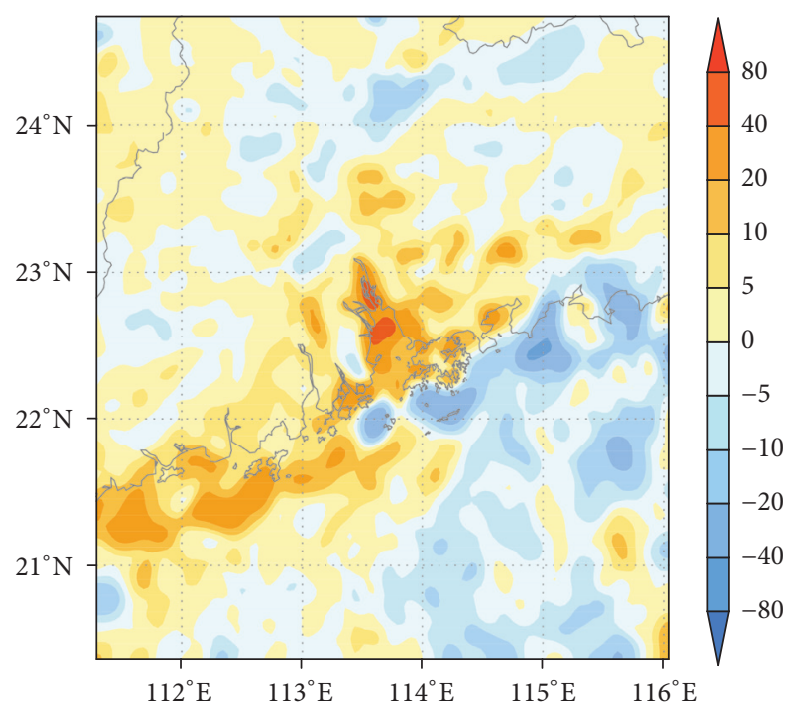

(d)

FIGURE 6: As in Figure 3, but for ground upward 1-h accumulated sensible heat fluxes (unit: $\mathrm{W} \mathrm{m}^{-2}$ ).

the BEP UCM to represent urban vertical structure. Outputs of the two tests were compared in terms of wind fields, precipitation, and temperature.

The results show that the areas with substantial changes in meteorological conditions coincided with urban expansion areas such as Guangzhou, Dongguan, and Shenzhen. Due to greater roughness, $10 \mathrm{~m}$ wind speed weakened considerably in urban areas and their suburbs, maintaining $\sim 3 \mathrm{~m} \mathrm{~s}^{-1}$ over the last two days of simulation, as expected. As a result of urbanization, precipitation was concentrated in the main precipitation belt north of the Pearl River estuary. The area upwind of the PRD city cluster showed weak decreases and the downwind side increases. Compared with wind and precipitation, the influence of urbanization on temperature appeared more complicated. Because of that influence, the PRD urban area had a weak decrease in temperature at night. In daytime, temperature change was strongly correlated with precipitation change. The PRD urban area exhibited a weak UHI with light precipitation on 1 January. In contrast, on 2 January, along with the considerable increase in precipitation, most urban areas of the PRD estuary showed a weak temperature decrease, except those southwest of the PRD estuary with light rain. The temperature changes could be mostly explained by the ground upward heat flux, which is directly affected by altered urban land use. That flux is comprised by ground upward sensible heat flux and ground upward latent heat flux. The ULHF was increased by urbanization, with intensity decreasing on 2 January. Because the relative humidity reached $100 \%$, the USHF was similar across the three daytime periods, with intensity persisting around $-40 \mathrm{~W} \mathrm{~m}^{-2}$. This means that the ground upward heat flux decrease was caused by the ULHF decrease on 2 January, 


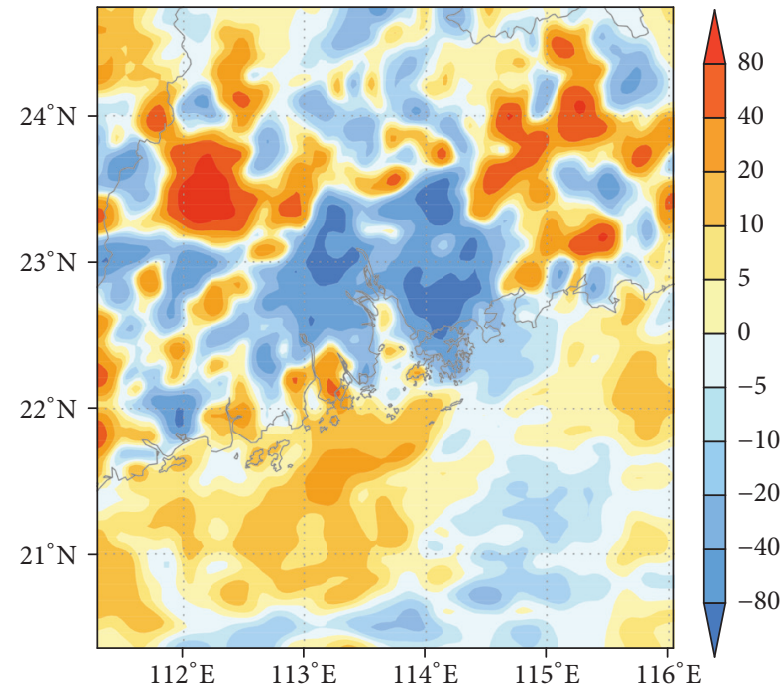

(a)

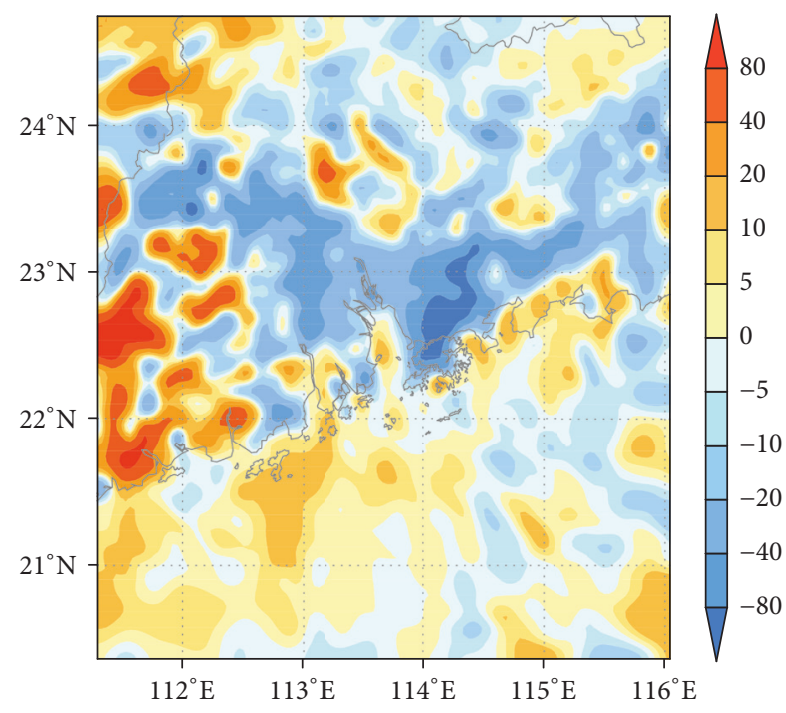

(c)

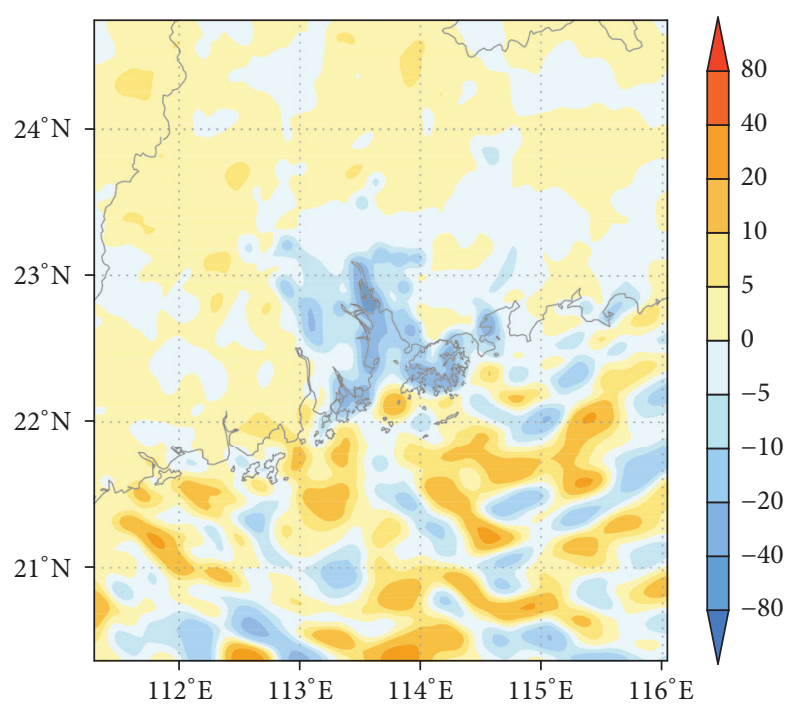

(b)

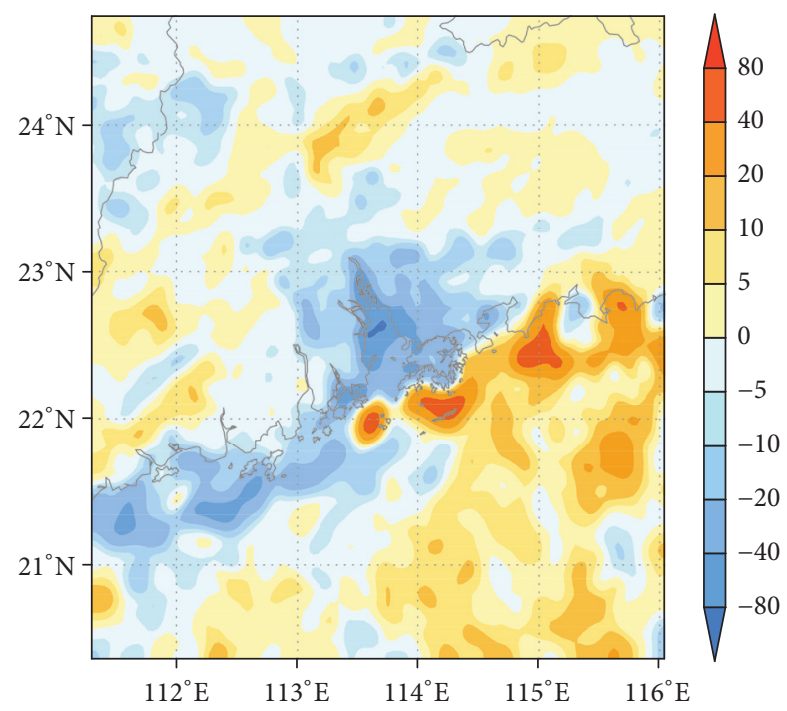

(d)

FIGURE 7: As in Figure 6, but for ground upward 1-h accumulated latent heat fluxes (unit: $\mathrm{W} \mathrm{m}^{-2}$ ).

which in turn caused an urban cold island during the daytime in some urban areas.

\section{Conflicts of Interest}

The authors declare that they have no conflicts of interest.

\section{Acknowledgments}

The numerical simulations were performed using supercomputers "Tianhe-2" of the National Supercomputing Center in Guangzhou. The authors are grateful to the NCAR Mesoscale and Microscale Meteorology Division for making the WRF-Chem model available at http://www.mmm.ucar .edu/wrf/users. The National Centers for Environmental Prediction Final Global Tropospheric Analysis (NCEP-FNL) data were taken from (https://rda.ucar.edu/datasets/ds083.2).
The study was funded by the National Program for Key Basic Research Projects of China (973) (Grant no. 2014CB953904), Natural Science Foundation of Guangdong Province (2015A030311026), and Guangzhou Science and Technology Plan (201605131033247).

\section{References}

[1] S. A. Changnon Jr. and F. A. Huff, "The urban-related nocturnal rainfall anomaly at St. Louis," Journal of Climate and Applied Meteorology, vol. 25, no. 12, pp. 1985-1995, 1986.

[2] X.-L. Chen, S.-J. Fan, J.-N. Li, J. Liu, A.-Y. Wang, and S.-K. Fong, "Typical weather characteristics associated with air pollution in Hong Kong area," Journal of Tropical Meteorology, vol. 14, no. 2, pp. 101-104, 2008.

[3] F. Chen, Z. Janjić, and K. Mitchell, "Impact of atmospheric surface-layer parameterizations in the new land-surface scheme 
of the NCEP mesoscale Eta model," Boundary Layer Meteorology, vol. 85, no. 3, pp. 391-421, 1997.

[4] C.-Y. Lin, F. Chen, J. C. Huang et al., "Urban heat island effect and its impact on boundary layer development and land-sea circulation over northern Taiwan," Atmospheric Environment, vol. 42, no. 22, pp. 5635-5649, 2008.

[5] J. C. F. Lo, A. K. H. Lau, F. Chen, J. C. H. Fung, and K. K. M. Leung, "Urban modification in a mesoscale model and the effects on the local circulation in the pearl river delta region," Journal of Applied Meteorology and Climatology, vol. 46, no. 4, pp. 457-476, 2005.

[6] R. D. Bornstein, "Observations of the Urban Heat Island Effect in New York City," Journal of Applied Meteorology and Climatology, vol. 7, no. 4, pp. 575-582, 1968.

[7] M. W. Rotach, "Profiles of turbulence statistics in and above an urban street canyon," Atmospheric Environment, vol. 29, no. 13, pp. 1473-1486, 1995.

[8] C. S. B. Grimmond and T. R. Oke, "Turbulent heat fluxes in urban areas: Observations and a local-scale urban meteorological parameterization scheme (LUMPS)," Journal of Applied Meteorology and Climatology, vol. 41, no. 7, pp. 792-810, 2002.

[9] D. Du, W. Lin, J. Li, D. Yang, and X. Ye, "Effect of land use change on summer monthly climate over the Pearl River Delta," Zhongshan Daxue Xuebao/Acta Scientiarum Natralium Universitatis Sunyatseni, vol. 49, no. 1, pp. 138-144, 2010.

[10] W. U. Xi, X. Wang, X. Zeng, and X. U. Li, "The effect of urbanization on short duration precipitation in beijing," Journal of Nanjing Institute of Meteorology, vol. 04, no. 1, pp. 177-190, 2000.

[11] X. Guo, D. Fu, and J. Wang, "Mesoscale convective precipitation system modified by urbanization in Beijing City," Atmospheric Research, vol. 82, no. 1-2, pp. 112-126, 2006.

[12] J. Hidalgo, G. Pigeon, and V. Masson, "Urban-breeze circulation during the CAPITOUL experiment: Observational data analysis approach," Meteorology and Atmospheric Physics, vol. 102, no. 3-4, pp. 223-241, 2008.

[13] C. P. Kim and D. Entekhabi, "Feedbacks in the land-surface and mixed-layer energy budgets," Boundary Layer Meteorology, vol. 88, no. 1, pp. 1-21, 1998.

[14] P. Bougeault and P. Lacarrère, "Parameterization of orographyinduced turbulence in a mesobeta-scale model," Monthly Weather Review, vol. 117, no. 8, pp. 1872-1890, 1989.

[15] W. C. Skamarock, J. B. Klemp, J. Dudhia, D. O. Gill, D. M. Barker, and W. Wang, A description of the advanced research wrf version 2, 2006, Available from Ncar; P.O. BOX 3000; BOULDER, CO,88, 7-25.

[16] G. A. Grell and D. Dévényi, "A generalized approach to parameterizing convection combining ensemble and data assimilation techniques," Geophysical Research Letters, vol. 29, no. 14, pp. 381-38-4, 2002.

[17] Y.-L. Lin, R. D. Farley, and H. D. Orville, "Bulk parameterization of the snow field in a cloud model," Journal of Applied Meteorology and Climatology, vol. 22, no. 6, pp. 1065-1092, 1983.

[18] F. Chen and J. Dudhia, "Coupling and advanced land surfacehydrology model with the Penn State-NCAR MM5 modeling system. Part I: model implementation and sensitivity," Monthly Weather Review, vol. 129, no. 4, pp. 569-585, 2001.

[19] E. J. Mlawer, S. J. Taubman, P. D. Brown, M. J. Jacono, and S. A. Clough, "Radiative transfer for inhomogeneous atmospheres: RRTM, a validated correlated-k model for the longwave," Journal of Geophysical Research: Atmospheres, vol. 102, no. 14, pp. 16663-16682, 1997.
[20] M. D. Chou and M. J. Suarez, "An efficient thermal infrared radiation parameterization for use in general circulation models," Technical Report Series on Global Modeling and Data Assimilation, Tech. Memo, Goddard Space Flight Center, Greenbelt, 1994. 

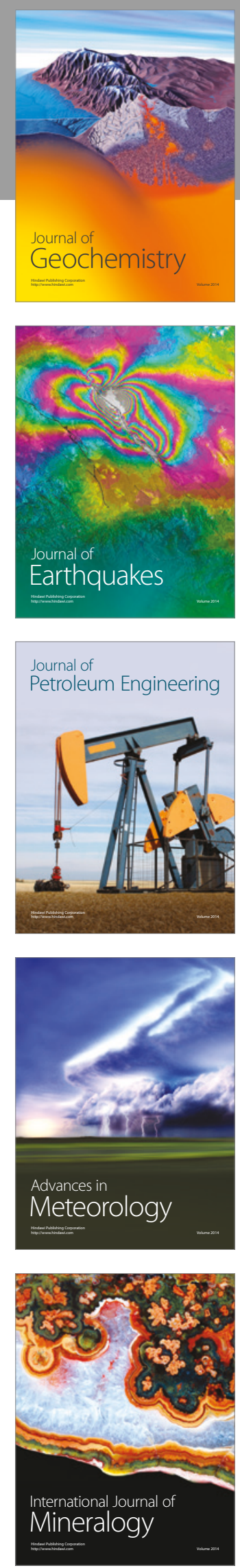
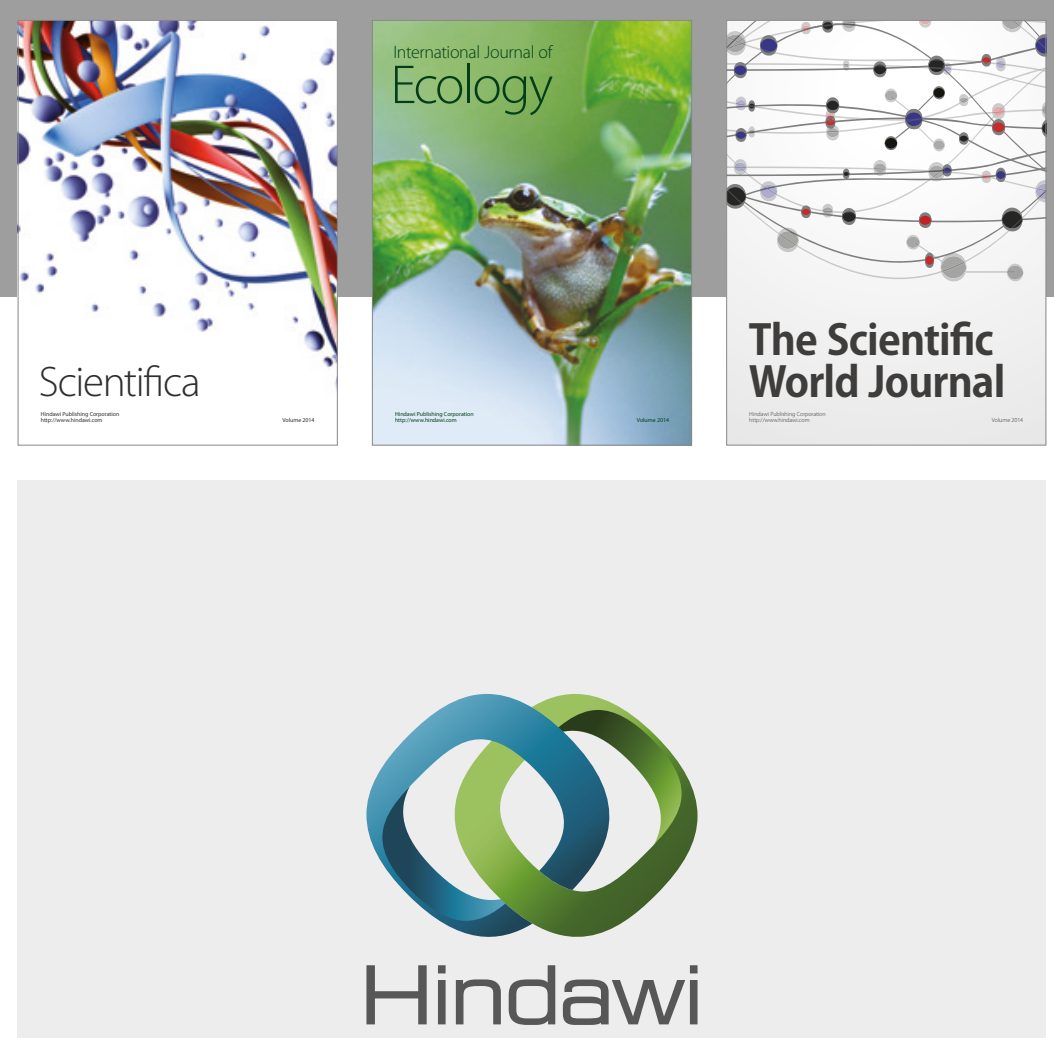

Submit your manuscripts at

https://www.hindawi.com
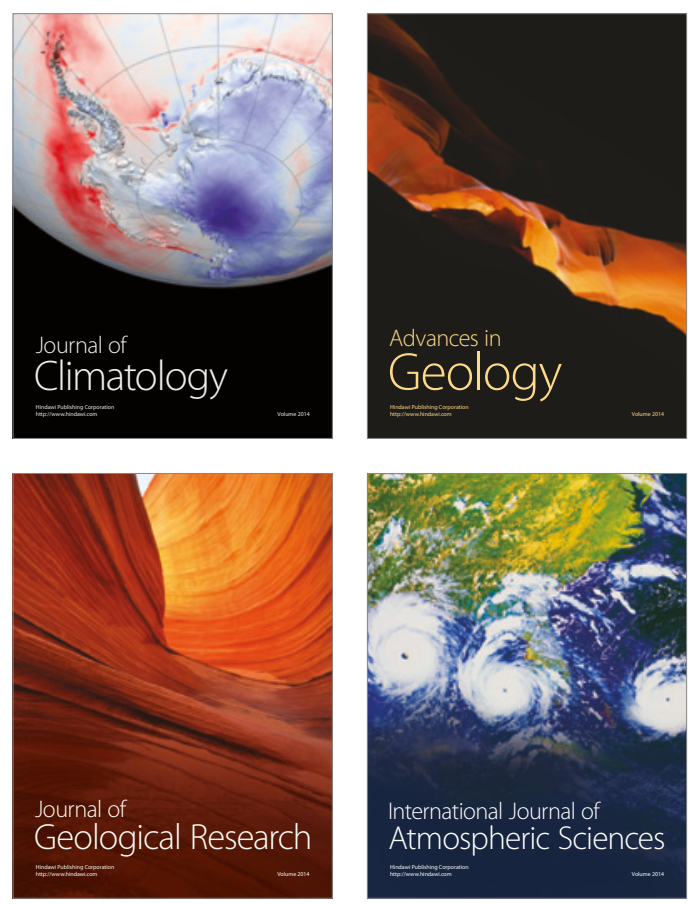

The Scientific

World Journal
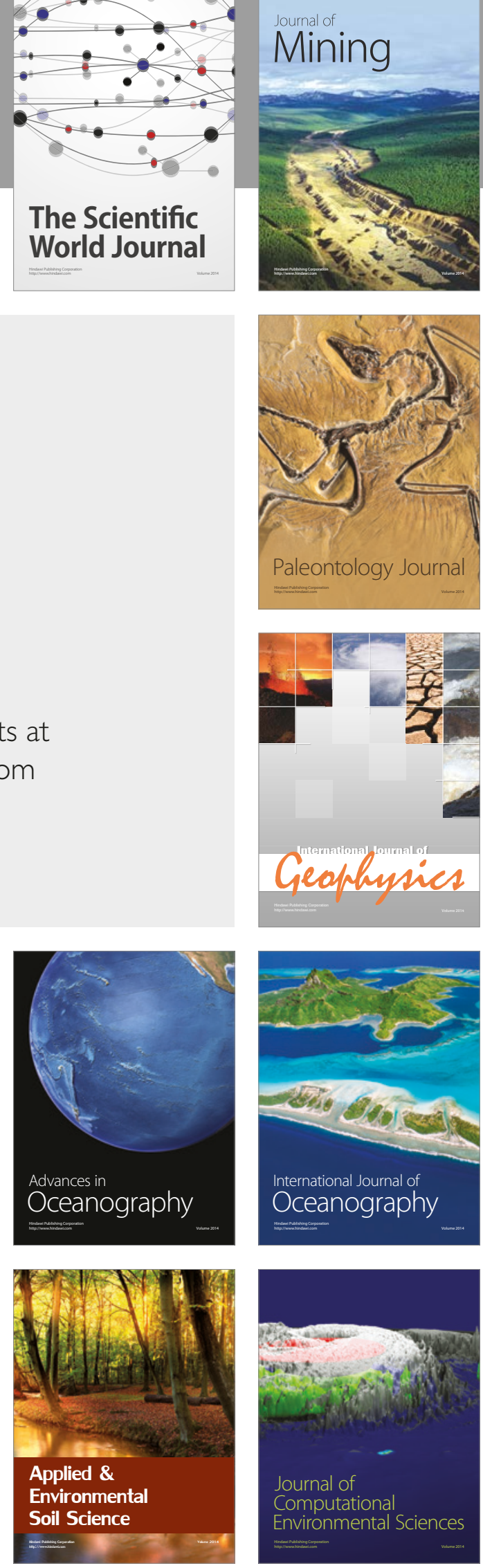